\title{
O PAPEL DO PROFESSOR EM CURSOS DE LÍNGUAS À DISTÂNCIA
}

\author{
Letícia Coelho Roland (UFRGS) - leticia@learningbrazilian.com
}

\section{RESUMO}

Preparar professores de línguas para suas carreiras é um processo complexo, que requer o desenvolvimento de diversas habilidades. Nos últimos anos, a fim de se promover um crescimento profissional, uma variedade de disciplinas têm sido incorporadas nos currículos das Licenciaturas de Línguas das universidades brasileiras. Dentre elas, todavia, poucas são aquelas relacionadas com tecnologias educacionais e, mais especificamente, com ensino-aprendizagem de línguas assistida por computador ou baseada na web. A Internet tem promovido muitas mudanças no mundo educacional, mas poucos cursos de formação de professores de línguas têm conseguido acompanhar a evolução dessa nova era. Como resultado, esses professores estão concluindo seus cursos ainda despreparados e, conseqüentemente, fazendo um mau uso do computador e da Internet, perdendo a oportunidade de usar uma ferramenta poderosa no ensino de línguas. Esse artigo discute a questão da formação do professor de línguas e sua atuação em cursos de língua à distância, utilizando recursos da Internet de uma forma comunicativa. Considerando-se a carência de materiais instrucionais direcionados ao professor de línguas no tocante ao uso pedagógico de diversas tecnologias emergentes, tais como blogs e podcasting, foi realizada uma breve análise de diversas ferramentas online, no intuito de auxiliar no processo de alfabetização digital desses profissionais.

Palavras-chave: aprendizagem de línguas assistida por computador, aprendizagem de línguas baseada na web, aprendizagem online de línguas, tecnologias educacionais.

\section{TEACHER'S ROLE IN ONLINE LANGUAGE COURSES}

\begin{abstract}
Preparing English teachers for their careers is a complex process which requires the improvement of a variety of abilities. To promote this professional growth, a variety of tasks have been incorporated into English teacher training programs in Brazilian universities during the last years. Among them there are a few courses related to educational technologies and, more specifically, to computer-assisted language learning (CALL) or web-based language learning. The Internet has promoted several changes in the educational field and few universities' programs have managed to follow the concepts of this new era. As a result, English teachers are still finishing their courses unprepared and consequently misusing the computer and the Internet, missing the opportunity to have a powerful tool in the language teaching process. This paper discuss language teachers' formation and their performance in online language courses when using some Internet tools in a communicative approach. Due to the lack of instrutional materials for language teachers who need to use emerging technologies, such as blogs and podcasting, some online tools were analysed in order to compose a helpful guide for language teachers in their proccess of digital literacy.
\end{abstract}

Keywords: computer-assisted language learning, CALL, web-based language learning, online language learning, educational technologies 


\section{INTRODUÇÃO}

Desde sua constituição histórica, a escola representa o local aonde os estudantes vão para serem ensinados. Esse conceito de escola se iniciou na Era Antiga e, com poucas mudanças, tem sido mais ou menos o mesmo até hoje. A escola foi definida como o lugar da Educação e cristalizou-se nessa forma rígida, na qual todo o sistema educacional foi baseado. Papert (1993) comenta que a maioria dos profissionais de um século atrás, se pudessem vislumbrar o presente, veriam que suas profissões foram radicalmente atualizadas; enquanto os professores perceberiam que o processo de ensinar foi superficialmente alterado, baseando-se ainda na tríade giz-quadro-livro.

Mesmo em face de todas as transformações do mundo pós-moderno, a escola ainda se mantém como um local imutável, que revive o dogma de 'lugar da Educação'. A introdução das tecnologias de comunicação e informação (TICs) em praticamente todas as esferas da sociedade moderna acelerou o processo de globalização, não só na economia mas também em todas as formas culturais. Além disso, determinou uma nova variação na definição de diversas profissões, requerendo novos tipos de conhecimento.

A Internet é talvez a face mais dinâmica das TICs e carrega grande potencial para uso educacional, especialmente para o ensino de línguas. A riqueza de interatividade e os recursos multimídia podem contribuir para motivar os estudantes, visto que promovem feedback personalizado e imediato, fazendo com que os alunos possam trabalhar de uma forma individualizada e em seu próprio ritmo. Além disso, Singhal (2006) ressalta que o conteúdo pode ser oferecido de uma forma não-linear, possibilitando aos estudantes selecionarem atividades e conceitos que eles desejam estudar ou revisar. De uma forma geral, os computadores diminuíram a importância da memorização e a hipertextualidade está anulando o pensamento linear, substituindo a página seqüencial por estruturas de múltiplas dimensões e despertando conexões entre diferentes tipos de conhecimento. Todas essas características não só aumentam a motivação do estudante como também contribuem pra aumentar a autonomia no processo de aprendizagem.

Para Levy (1997), os computadores trouxeram uma nova tecnologia intelectual, que pode ser comparada ao que aconteceu com o surgimento da escrita ou da imprensa, pois trouxe uma nova forma de se pensar o mundo e novos pontos de vista, o que conseqüentemente trazem novas formas de lidar com o conhecimento e os processos de aprendizagem. Por isso, o professor tem que se (re)inventar, para evitar ser substituído. Warschauer e Whittaker (1997) comentam que a tecnologia tem se atualizado tão rapidamente que os professores têm dificuldades em acompanhá-la e se manterem atualizados ou, até mesmo, de simplesmente escolherem dentre as diversas ferramentas oferecidas.

De certa forma, os desenvolvedores de sistemas de aprendizagem de línguas assistida por computador (CALL) ou baseada na web têm explorado as tecnologias emergentes e se focado na aplicação dessas tecnologias no desenvolvimento dos seus cursos. Isso acontece, porém, sem que seja dado ao professor um treinamento específico no uso de tais tecnologias. Pode-se dizer que já se percebeu a necessidade de reformulação dos materiais de aprendizagem, porém, agora, é necessário perceber a importância de uma reformulação na prática de ensino. Hampel e Stickler (2005) comentam que todos os custos, bem como o esforço, ao se desenvolver material online pode ser desperdiçado sem o treinamento adequado de professores, que saibam trabalhar com esse material, explorá-lo de forma correta para que suportem devidamente o processo de aprendizagem.

Zheng (2005) define que um professor online de inglês deve ter quatro macrohabilidades: ser digitalmente alfabetizado, ser um pensador criativo, ter multi- 
habilidades e ser um facilitador da aprendizagem. Em relação à alfabetização digital, as qualidades do professor podem ser definidas em seis habilidades, a saber:

1) Definir os objetivos das tarefas;

2) Localizar fontes de dados;

3) Selecionar dados úteis;

4) Processar informação;

5) Apresentar informação;

6) Avaliar precisamente as tarefas.

Hampel e Stickler (2005) reforçam que professores online de línguas precisam ter qualidades diferentes daquelas normalmente encontradas em um professor competente e que também vão além daquelas encontradas em professores online de outros conteúdos.

Apesar disso, a maioria dos cursos de formação de professores de línguas do Brasil ainda não entendeu a importância das TICs no ensino de línguas e não têm adotado estratégias apropriadas em resposta às mudanças que nossa sociedade tem vivido. Numa análise dos currículos dos cursos de Licenciatura em Inglês de onze universidades públicas ${ }^{\mathrm{ii}}$, encontrei uma única disciplina obrigatória relacionada à aplicação das tecnologias no ensino de línguas em dois cursos diferentes (UFRGS, 60 horas; UFSM, 30 horas). Disciplinas alternativas são oferecidas nesses e em dois outros cursos (UnB, 30 horas; UFMA, 45 horas), mas se focam em informática ou multimídia na educação de uma forma geral, não sendo especificamente relacionadas ao ensino de línguas.

Isso pode significar que os futuros professores de línguas, formados em algumas das universidades mais importantes do país, não estão sendo corretamente preparados para lidar com os novos recursos já utilizados (ou ao menos disponíveis) nas salas de aulas das universidades, dos cursos privados de línguas, das escolas particulares e de algumas escolas públicas. Especialmente os cursos privados e as escolas particulares, que costumam ser os principais empregadores dos profissionais recém-formados, estão constantemente investindo em novas tecnologias para competir no mercado.

Considerando-se o fato de que a didática e metodologia dos ensinos de línguas discutidas nas salas de aula dos cursos de graduação são focadas no uso de recursos como giz, quadro-negro e livro-texto e, quando muito, tocadores de áudio e/ou televisão, vídeo-cassete ou DVDs, como estão agindo os professores de língua inglesa quando são solicitados pelos coordenadores a utilizar a Internet em sua prática pedagógica? Esse artigo surgiu a partir da minha curiosidade em saber como o professor de línguas, mais especificamente o professor de inglês, está lidando com essa situação.

A importância desse artigo se deve ao fato de que as tecnologias educacionais e os sistemas construtivistas de CALL são conceitos ainda novos para os professores brasileiros de línguas. Quando os professores precisam usar as novas tecnologias em suas aulas ou conduzirem uma aula online, eles normalmente aplicam as mesmas técnicas usadas em atividades feitas em aulas presenciais ou tendem a aplicar métodos comportamentalista de ensino. Zheng (2005) comenta que algumas pessoas ainda acreditam que CALL se refere somente aos drills e aos exercícios mecânicos. Hoje em dia, contudo, CALL pode oferecer suporte altamente interativo e comunicativo para compreensão oral, fala, leitura e escrita, incorporando o uso extensivo da Internet. Realmente, os professores associam as atividades no computador aos drills ${ }^{\mathrm{iii}}$, enquanto o computador é, na verdade, uma ferramenta poderosa e que pode ser explorada de uma forma construtivista e comunicativa.

Além disso, a literatura sobre treinamento e formação de professores online está focada, principalmente, em questões técnicas e no conhecimento de ferramentas 
específicas, sem considerar a aplicação construtivista e comunicativa que se pode dar a essas ferramentas. Bennett e Marsh, citados por Hampel e Stickler (2005), apontam duas habilidades importantes que vão além da capacidade técnica: (i) identificar o contexto de ensino-aprendizagem e as diferenças e semelhanças significativas entre a abordagem presencial e a online e (ii) identificar estratégias e técnicas que facilitem a aprendizagem online, ajudando os estudantes a explorar as vantagens em relação à aprendizagem tanto colaborativa quanto autônoma. Hampel e Stickler (2005), por sua vez, complementam as idéias daqueles autores, destacando que professores de línguas também necessitam desenvolver a habilidade de (iii) criar comunidades online ou realidade social para a aprendizagem de línguas.

Sendo assim, nesse artigo analisei diversos recursos facilmente encontrados na Internet e que podem ser utilizados em aulas de línguas, com foco em aulas de inglês. A partir dos comentários de Hampel e Stickler (2005) em relação às habilidades necessárias aos professores online de línguas, previamente citadas, tais ferramentas foram (i) analisadas em contraste com a utilização de recursos semelhantes em aulas presenciais; (ii) destacadas quanto às vantagens que trazem à aprendizagem de línguas; (iii) inspecionadas quanto à capacidade de contribuir para formação de interações sociais entre os aprendizes. Com isso, acredito que esse artigo possa servir como um guia inicial para os professores que buscam se alfabetizar nas novas tecnologias e tirar bom proveito desses recursos, explorando-os de uma forma construtivista e comunicativa.

\section{TRANSFORMANDO FERRAMENTAS DA INTERNET EM RECURSOS CONSTRUTIVISTAS E COMUNICATIVOS}

Se expressar apropriadamente numa interação é o objetivo da maioria dos estudantes de línguas. A fluência ao falar ou a precisão ao escrever, contudo, só são melhoradas através da prática em diferentes contextos, com uma quantidade elevada de tópicos diversos e pela utilização de múltiplas habilidades. A Internet pode oferecer essas condições, propiciando aos estudantes que se encontrem nos mais diversos contextos, trabalhando com tópicos variados e utilizando habilidades múltiplas. Para que isso aconteça, contudo, é necessário que o professor de línguas saiba conduzir apropriadamente as interações entre os alunos no ambiente online.

Para realizar corretamente o seu papel, os professores online não podem focar-se somente em ajudar os estudantes a desenvolver suas habilidades técnicas em relação ao sistema virtual de aprendizagem, mas também serem conscientes dos benefícios e desafios da educação à distância. Eles devem estar familiarizados com as tecnologias a serem usadas e, principalmente, saberem a implicação que cada mídia tem no contexto do ensino de línguas. Eles devem integrar suas habilidades como professor de línguas ao conhecimento técnico de informática para alcançarem uma simbiose única, útil ao contexto online de aprendizagem de línguas, focando o método comunicativo.

Sendo assim, analisarei algumas ferramentas disponíveis na Internet, que podem ser sabiamente utilizadas na aprendizagem online de línguas.

$\underline{\text { Recursos básicos }}$

Podemos definir como recursos tecnológicos básicos aqueles mais comumente utilizados e cujo uso na Internet já é recorrente e de muito fácil acesso. Seriam eles:

- Chats;

- Emails;

- Listas de discussão.

Nesse artigo iremos falar sobre os recursos básicos de uma forma integrada, visto que diversas atividades desenvolvidas podem ser aplicadas através do uso dessas 
três ferramentas.

Os chats são qualquer tipo de comunicação síncrona baseada na Internet, inicialmente referindo-se à interação um-a-um apesar de também ser possível comunicar-se com diversos falantes ao mesmo tempo. $\mathrm{O}$ chat pode acontecer tanto em 'salas' específicas para isso, que são normalmente organizadas em torno de um identificador (cidade, idade, interesse específico) ou ainda em programas de mensagens instantâneas, conhecidos como messengers.

Em relação à aula presencial, as salas de chat oferecem a possibilidade de se comunicar com um falante nativo da língua ou com algum estudante que esteja apto a se comunicar na língua-alvo sem a interferência de estruturas da língua portuguesa. Trabalhos colaborativos com outros professores de inglês podem ser organizados através de salas de chat, integrando alunos de níveis similares mas de diferentes locais do Brasil ou do mundo.

Os programas de mensagens instantâneas se tornaram populares a partir do lançamento do ICQ em novembro de 1996. Como comumente acontece com o surgimento de uma tecnologia nova, os provedores de serviços de Internet começam a oferecer um serviço assim que ele se torna popular. Dessa forma, AOL, Yahoo e Microsoft alavancaram a popularidade desse tipo de programas e incluíram diversas novas capacidades, tais como chat com múltiplos usuários, recursos multimídia (emoticons, áudio e vídeo) e troca de arquivos. A versão mais recente do MSN, messenger da Microsoft, conta com compartilhamento de tela e navegação conjunta na Internet.

Os emails são recursos eletrônicos que permitem o envio e recebimento de mensagens de texto através da Internet (apesar do termo também ser utilizado para mensagens via intranets). $\mathrm{O}$ email foi a primeira ferramenta que possibilitou a troca de mensagens eletrônicas entre pessoas separadas fisicamente e sua criação data da década de 60 (Wikipedia, 2006). Com a popularização da Internet, as mensagens começaram a poder ser lidas através do navegador e muitos serviços de emails gratuitos apareceram.

As listas de discussão são um meio de comunicação muito similar às salas de chat, porém são fundamentalmente assíncronos, ou seja, os envolvidos não precisam necessariamente estar conectados ao mesmo tempo. Também, as listas de discussão oferecem interação entre múltiplos usuários. Assim, um participante escreve uma mensagem que será respondida ou comentada futuramente pelos outros participantes.

Por propiciar uma comunicação síncrona, uma das peculiaridades dos chats é o dinamismo na interação entre os envolvidos, ao contrário do email e das listas de discussão. Estes últimos, por sua vez, podem servir para aumentar a segurança do aluno ao produzir suas falas na língua-alvo, visto que ele tem mais tempo para organizar suas idéias e estruturar suas sentenças. O chat, todavia, usualmente tem uma linguagem menos formal e mais próxima à linguagem falada, onde os erros, tanto gramaticais quanto de ortografia, são mais bem aceitos.

Num estudo que investigou a aquisição de habilidades de fala em um curso online de línguas, Volle (2005) concluiu que as tarefas síncronas e as entrevistas orais (que podem ser feitas através dos chats) são experiências valiosas para os estudantes, além de fornecer um registro permanente do desenvolvimento das habilidades do estudante. Também, Payne e Ross (2005) comentam que evidências revelam que a comunicação síncrona via texto pode desenvolver indiretamente habilidades de fala numa segunda língua e, mais importante, pode auxiliar especialmente aqueles estudantes com limitações na capacidade mnemônica. Enfim, em suma, experiências usando chat estimulam uma comunicação autêntica e auxiliam os estudantes a desenvolverem habilidades específicas de comunicação, tais como contraposição, 
argumentação e persuasão.

De acordo com Barson et al. (1993), muitos estudos colaborativos baseados em troca de emails foram desenvolvidos por estudantes de francês em nível intermediário das universidades de Harvard e Stanford no início da década de 90. Na maioria desses estudos, o objetivo final era a publicação de uma revista e o contato entre os alunos, o planejamento e o desenvolvimento dos textos foi realizado através da troca de emails. Experimentos similares ocorreram entre as universidades de Harvard e Pittsburgh (1990) e Stanford e Pittsburgh (1991-1993). Os autores acreditam que esse tipo de atividade, através da comunicação à distância e baseada em tarefas orientadas, tem mérito considerável para ser classificada como comunicativa e pode ser aplicada em diversos níveis.

Tecnologias emergentes

As tecnologias emergentes seriam aquelas que se tornaram populares mais recentemente e ainda causam surpresa, estranheza ou dificuldade de acesso para algumas pessoas. Acredito que podemos dizer que, atualmente, as ferramentas abaixo são consideradas emergentes na Internet:

- Blogs;

- Multimídia: podcasting e vídeo;

- Wikis.

Os blogs ou weblogs são publicações online que consistem de artigos periódicos, normalmente em ordem cronológica reversa, sendo mostrado aquele mais recente. Geralmente os blogs se focam em algum assunto específico, tal como literatura, comida, música, cultura ou política. Ainda, é muito comum encontrar blogs que são usados como um diário, onde o(s) autor(es) expõem sua vida ou seu ponto de vista sobre assuntos variados, ou relata $(\mathrm{m})$ alguma experiência, tal como viagem, intercâmbio, estágio, dentre outros. Na Wikipedia (2006) está definido que um blog típico combina texto, imagens e links para outros blogs, web pages e outras mídias relacionadas ao seu tópico.

As primeiras versões dos blogs eram atualizadas manualmente, requerendo conhecimentos como construção de páginas da Internet, disponibilização dos arquivos em algum servidor e, talvez, alguma linguagem de programação. Hoje em dia, contudo, foram criadas ferramentas para automatizar a manutenção dos blogs, tornando-os muito mais acessíveis à população em geral. Além disso, houve também uma simplificação no processo de criação visual e de inserção de multimídias. Os blogs podem ser hospedados por serviços dedicados a isso (Blog, LiveJournal) ou nos diversos serviços que começaram a ser oferecidos por provedores de serviços da Internet, tais como MSN e Yahoo.

Analisando-se inicialmente a estrutura do blog podemos perceber que ele pode ser usado como uma fonte rica de material autêntico em inglês, uma vantagem que a Internet traz ao professor de línguas. Esse material estará provavelmente organizado de uma forma estruturada, centrado em um tema e complementado com recursos multimídia diversos. Porém, o blog pode ser muito mais que isso. Os bloggers (autores do blog) normalmente oferecem aos seus leitores a possibilidade de interação, sendo que o leitor pode inserir um feedback ao autor, trocando idéias, complementando as idéias do autor ou mesmo discordando do conteúdo do blog. Nesse sentido, essa interatividade oferece uma condição perfeita para a discussão sobre tópicos de interesse, onde serão necessárias habilidades como organização de estruturas, argumentação, desenvolvimento de idéias, dentre outras.

Ainda, o aluno de inglês pode passar do papel de simples leitor de blogs para a condição de autor de seu próprio blog, tanto de uma forma mais individualizada ou 
colaborativa. As atividades de troca de emails previamente relatadas por Barson et al. (1993) podem ser recriadas, hoje em dia, utilizando-se não só o email, mas também o chat, que tornaria as interações mais dinâmicas e mais rápidas, melhorando a comunicação e a troca de idéias. Além disso, a revista poderia ser organizada no formato de um blog.

Existem diversas outras formas de se usar blogs ${ }^{\text {iv }}$ no ensino de línguas:

1) Jornais. Os jornais têm sido largamente usados no ensino presencial de línguas. Um blog pode ser a recriação em formato digital de tais jornais, aumentando a motivação do estudante pelo fato de escrever não só para o professor e colegas de classe. A interatividade trazida pela troca de mensagens com os leitores do jornal pode encorajar o estudante a escrever com mais acuidade, preocupando-se com seu estilo de escrita, devido à presença de leitores reais.

2) Tarefas online. Cursos online nos quais os professores e alunos estão separados geográfica e temporalmente utilizam-se de blogs para centralizar as informações sobre o curso e dispor as atividades a serem realizadas pelos alunos.

3) Pesquisas e enquetes. Os blogs podem ser usados para coletar dados que seriam impossíveis de serem coletados de forma presencial, devido, por exemplo, à distância entre o pesquisador e o público-alvo. Isso pode ser útil para se aprender sobre questões culturais, sendo que os entrevistados podem ser falantes nativos da língua-alvo.

Podemos definir recursos multimídia como aqueles que apresentam mais do que um tipo de mídia em uma única apresentação, ou seja, o uso concomitante de texto, imagens, áudio e vídeo. Atualmente na Internet encontramos diversos recursos multimídia, sendo o podcasting e o vídeo em demanda (VoD, sigla de video on demand) duas tecnologias emergentes em que se exploram recursos multimídia.

De acordo com a Wikipedia (2006), "podcasting é um método de distribuir arquivos multimídia, tais como áudio e vídeo, através da Internet, para ser acessado em computadores, dispositivos móveis, tocadores de mp3 ou computadores portáteis". O objetivo do podcasting é criar conteúdo de áudio ou vídeo para uma audiência que quer acessar esses recursos a qualquer momento e de qualquer local. O podcasting foi associado primeiramente a arquivos de áudio, mas o rápido desenvolvimento da tecnologia logo permitiu a distribuição de conteúdos em vídeo, conhecidos como vodcasting.

Os podcasters (autores do podcast) podem oferecer os arquivos para download ou em tempo real. Normalmente o podcast é uma entrevista ou ao menos está focada em algum tópico, com novos episódios oferecidos em intervalos planejados. Existem diversas redes de podcasting, que oferecem múltiplos tópicos ao mesmo tempo ou download de tópicos variados.

A idéia inicial do podcasting era permitir que os usuários distribuíssem seus próprios programas de rádio, mas o sistema está sendo usado cada vez mais para outras finalidades, incluindo propósitos educativos. Em 2004, a Musselburgh Grammar School, disponível em http://www.mgsonline.org.uk/ foi a precursora em utilizar os recursos do podcasting na revisão de conteúdos e nos deveres de casa de um curso de línguas. Outra pioneira no uso educacional de podcasting foi a rádio WillowWeb, disponível em http://www.mpsomaha.org/willow/radio, um podcast especial feito por e para crianças. Atualmente existem diversos projetos de podcasting especialmente desenvolvidos para o ensino de inglês. Dentre eles, analisei os seguintes:

1) Podcast.com, disponível em http://www.podcast.com - portal de podcasting, 
contendo distribuição de arquivos em diversos temas, tais como arte, cultura, educação, comida, esportes, viagens e outros;

2) UGo\&IGo, disponível em http://ugoeigo.skuldtek.com - vodcasting com frases em inglês, organizadas em torno de um eixo temático. O autor está desenvolvendo uma seção em que os usuários podem enviar pedidos de palavras ou expressões para serem reproduzidas;

3) ELT podcast, disponível em http://www.eltpodcast.com - oferece arquivos de áudio de conversações em diversos níveis, juntamente com sua transcrição. As conversações são oferecidas em dois ritmos, um mais pausado e outro que reproduz a velocidade normal da fala;

4) Just Vocabulary, disponível em http://www.justvocabulary.libsyn.com - o autor analisa diariamente dois vocábulos da língua inglesa, exemplificando seu uso correto e pronúncia. De tempos em tempos ele ainda oferece um teste sobre os vocábulos analisados.

Tanto podcasting como vodcasting podem oferecer aos estudantes a chance de estar em contato com material autêntico em língua inglesa. Com a exploração dos podcasts destinados ao ensino do inglês, pode-se organizar um estudo mais estruturado e centrado no aluno, além da possibilidade de colocar o estudante em contato com os autores de tais podcasts, que geralmente são professores de inglês nativos. Além disso, assim como no caso dos blogs, o estudante pode se tornar o provedor do podcasting, o que pode ser muito motivador.

Wikis são um tipo de página da Internet que permite aos usuários facilmente adicionar, remover ou editar conteúdo. Essa facilidade de interação e operação tornou a wiki uma ferramenta efetiva na elaboração de textos colaborativos. Em sua essência, a wiki é uma simplificação do processo de criação de páginas da web, combinada com um sistema que grava cada alteração que ocorre ao longo do tempo, de maneira que a página pode ser revertida para uma versão anterior a qualquer momento (Wikipedia, 2006).

O sistema wiki pode oferecer várias ferramentas que auxiliam os usuários colaboradores a checarem constantemente os estados de alteração e, bem como, espaços para discussão entre os diversos colaboradores, a fim de se resolver impasses ou desentendimentos sobre o conteúdo da wiki. A maioria dos sistemas oferece acesso irrestrito aos usuários colaboradores, o que torna a escrita colaborativa e coletiva uma atividade muito simples e que necessita somente de um navegador.

Wikipedia, disponível em http://www.wikipedia.org é uma das páginas de wikis mais famosas. Ela é uma enciclopédia de conteúdo livre que é escrito colaborativamente por voluntários, permitindo que os artigos sejam alterados por qualquer pessoa com uma conexão à Internet. Atualmente, a enciclopédia contém mais de quatro milhões de artigos em diversas línguas, sendo que mais do que um milhão e meio estão em inglês.

Como as wikis são escritas livremente, o professor de línguas deve acompanhar a consulta dos alunos ao conteúdo das mesmas. É nessa hora que o professor deve utilizar sua habilidade, previamente proposta por Zheng (2005), de saber selecionar dados úteis. As wikis podem auxiliar os estudantes a desenvolver habilidade de leitura e seleção de conteúdo, através da busca de diversos tópicos. Além disso, eles podem pesquisar conteúdo na web, organizar seus próprios textos e colaborar em algum sistema wiki. Falando sobre uma atividade similar, Singhal (2006) comenta que uma vez que a informação foi obtida, os estudantes necessitam revê-la, o que requer o desenvolvimento de habilidades tais como scanning, seleção e avaliação de conteúdo. 


\section{CONCLUSÃO}

A escola, como qualquer outra instituição social, sofre as mesmas transformações que a sociedade como um todo. Uma de suas missões é qualificar estudantes para interpretarem o mundo através de seus conhecimentos e habilidades. No sistema educacional, a importância dos mediadores, tais como o livro didático ou os recursos multimídia, tem sido reconhecida. Todavia, atualmente, o conhecimento e a informação são capturados e distribuídos através de recursos diversos, que vão desde os textos impressos até áudio e vídeo distribuídos pela Internet. O aparecimento de cada recurso novo transforma e enriquece os tipos de representação, contribuindo para a transformação do processo social, cultural e econômico.

Zheng (2005) comenta que, se nós queremos estar preparados para os desafios educacionais do século 21, é fundamental que as instituições educacionais apliquem os conceitos fundamentais das TICs no desenvolvimento das suas aulas. Porém, para alcançar esse objetivo, novos papéis devem ser desempenhados por professores e alunos.

Acredito que a 'pedagogia online' é algo totalmente novo para os professores de língua brasileiros. Apesar da maioria dos problemas e desafios encontrados serem os mesmos, ou muito semelhantes, aqueles encontrados em aulas presenciais, há características específicas no ensino-aprendizagem de línguas através da Internet, quer seja em cursos total ou parcialmente online, que precisam ser percebidos e respeitados pelos professores de línguas.

Considerando-se que alguns problemas necessitam soluções diferentes daquelas aplicadas no ensino presencial, é importante prestar atenção nas necessidades de formação e treinamento dos professores de línguas, visto que a demanda de atuação em cursos à distância está aumentando.

Para começar, nesse artigo, procurei destacar a importância em se oferecer disciplinas que tratem de discutir o uso de novas tecnologias no ensino de línguas ${ }^{\mathrm{v}}$, nos cursos de formação de professores nas universidades brasileiras. Essas disciplinas precisam ressaltar as diferenças entre as técnicas de ensino presencial e online, a fim de facilitar a inserção do professor de línguas no mercado de trabalho em cursos à distância. Auxiliar os professores de línguas a entender as novas tecnologias disponíveis na Internet e seu uso pedagógico, de forma construtivista e comunicativa, contudo, é somente o primeiro passo. Mais trabalhos focando a formação do professor de línguas em contextos digitais são necessários.

Por isso, no intuito de auxiliar os professores que buscam se 'alfabetizar digitalmente', defini e analisei algumas ferramentas da Internet, sobretudo aquelas emergentes e que ainda não estão sendo amplamente utilizadas, identificando seu uso no contexto de cursos de línguas total ou parcialmente online. Dessa forma, esses professores podem ter um primeiro contato com tais ferramentas, entendendo como utilizá-las de forma construtivista e comunicativa em seus processos pedagógicos.

Ressalto que, além das habilidades fundamentais necessárias às aulas presenciais, os professores online de línguas devem estar preparados para alterar e adaptar seu modo de ensinar de acordo com as novas tecnologias e os novos achados da pedagogia e da informática. Além disso, sugiro que as instituições que oferecem cursos à distância de línguas se preocupem em oferecer aos seus professores um treinamento contínuo em relação às necessidades específicas de tal contexto de ensino, visto que eles não estão saindo das universidades brasileiras preparados para tal realidade. 


\section{REFERÊNCIAS}

BARSON, John; FROMMER, Judith; SCHWARTZ, Michael. Foreign language learning using e-mail in a task-oriented perspective: Interuniversity experiments in communication and collaboration. Journal of Science Education and Technology, v. 2, n.4, p.565-584, December 1993.

HAMPEL, Regine; STICKLER, Ursula. New skills for new classrooms: training tutors to teach languages online. Computer Assisted Language Learning, v. 18, n. 4, p.311326, October, 2005.

LEVY, P. A Máquina Universo. Criação, cognição e cultura informática. Porto Alegre: Artmed, 1997.

PAPERT, S. The Children's Machine: Rethinking School in the Age of the Computer. New York: BasicBooks, 1993.

PAYNE, J Scott; ROSS, Brenda M. Synchronous CMC, working memory, and L2 oral proficiency development. Language Learning \& Technology, v.9, n.3, p. 35-54, September, 2005.

SINGHAL, Meena. The Internet and Foreign Language Education: Benefits and Challenges. Disponível em: http://www.gse.uci.edu/ed168/resume.html. Acessado em: 25 março 2006.

VOLLE, Lisa M. Analyzing oral skills in voice e-mail and online interviews. Language Learning \& Technology, v. 9, n.3, p.146-163, September, 2005.

WARSCHAUER, Mark; WHITAKKER, Fawn. The Internet for English teaching: Guidelines for teachers. TESL Reporter, v.30, n.1, p.27-33, 1997.

ZHENG, Tongtao. Designing online Chinese language courses: new roles for educators. Journal of Information Technology Education, v.4, n.2, p.275-285, 2005.

\footnotetext{
${ }^{\text {i }}$ Pierre Levy comenta que uma tecnologia intelectual não precisa ser efetivamente usada pela maioria das pessoas para ser considerada dominante. Para ser entendida como uma tecnologia intelectual é importante que ela propicie mudanças profundas nos pontos de vista da sociedade (LEVY, 1997).

ii Os currículos analisados foram aqueles referentes à Licenciatura Plena em Língua Inglesa das seguintes universidades públicas: UFRJ, UnB, Unicamp, USP, UFMG, UEM, UFU, FURG, UFSM, UFMA e UFRGS.

iii Drills são exercícios de caráter comportamentalista, baseados na memorização, e que desconsideram o caráter comunicativo da língua.

${ }^{\text {iv }}$ Mais idéias sobre o uso de blogs como ferramentas educacionais podem ser encontradas na página da Internet do suplemento educacional Times, disponível em http://www.tes.co.uk/blogs (em inglês).

${ }^{\vee}$ A seção Modern Foreign Languages Environment da homepage Learning and Teaching Scotland, disponível em http://www.ltscotland.org.uk/mfle/index.asp discute sobre o uso de tecnologias no ensino e aprendizagem de línguas e em CALL. Eu recomendo, em especial, o link intitulado Creative Teaching.
} 